\title{
Strengthening primary healthcare in India: white paper on opportunities for partnership
}

\author{
Mala Rao and David Mant explore how India and the UK can work together on education, \\ professional development, affordable technologies, public-private partnerships, governance, \\ and innovation in primary care in India
}

\section{Executive summary}

The India-UK CEO Forum was established by the British and Indian prime ministers in July 2010 to seek to increase substantially trade and investment between the UK and India and promote greater collaboration. Health has been identified as one of the priority areas for the two countries to work more closely together. As part of this work, which is led by Mark Walport for the CEO Forum, the Wellcome Trust hosted a roundtable discussion on 14 September 2011 in the UK to explore the scope for India-UK collaborations in primary care. It was agreed at the meeting that a "white paper" should be developed, setting out the challenges and opportunities for the UK and India to work together in the area of primary care.

This “white paper” outlines a number of opportunities for collaborative action of benefit to both nations: strengthening primary care in India and bringing expertise in new technology and service innovations from India to improve care in the UK. It provided the basis for a two day workshop held in New Delhi, India on 23-24 February 2012, jointly hosted by the Wellcome Trust, the Government of India Ministry of Health and Family Welfare, and the UK Department for International Development.

\section{Overall strategic analysis}

- It is expected that India's 12 th five year plan (2012-17) will focus on health and recommend the strengthening of primary care as a key means to delivering this goal. The development of a UK-India partnership to strengthen primary care would enable the India UK CEO forum to contribute significantly to India's highest priority for health improvement as well as the enhancement of primary care in the UK National Health Service (NHS).

- India has the potential to take the lead internationally in the employment of affordable diagnostics and information technology in primary care to reduce health care costs, empower its population to selfmanage their own illnesses, and deliver care more effectively in remote areas.

- India has the major strategic advantage of a world leading generic pharmaceutical industry which is able to produce safe and effective drugs and vaccines at low price. It needs to exploit this opportunity and a strong primary care sector would do this.

- The NHS model of providing universal primary health care through public-private partnership (PPP) (particularly outcome based commissioning of primary care services from private providers) may be appropriate for adaptation in the Indian context.

- Continuing economic growth will be accompanied by a growing public demand for primary care delivered with high quality at affordable cost. A multidisciplinary team approach based on multiskilling and enhanced roles for nurses and other clinicians plus decentralised planning is necessary.

- Achieving high quality at affordable cost will require training of primary care teams to deliver effective evidence based preventive and chronic care outside hospital; they will also need training and support to be effective in guiding and prioritising hospital referral.

- In India there is a shortage of high calibre senior staff in primary care to act as trainers and role models. Developing the required cadre of primary care doctors, nurses, and other staff will therefore need the strong support of hospital clinicians.

- Enabling some of the primary care clinics to become centres of excellence will begin to meet the need for seeding high quality teachers and researchers in primary care.

\section{Summary of partnership opportunities}

Education and training-Training in primary care needs to extend across all health professional disciplines including doctors, nurses, managers, and allied health professionals. It could be facilitated by partnership with UK providers including the universities, royal col- leges, and medical publishers. This has the dual benefit of providing additional training opportunities in primary care for NHS trainees.

Professional recognition and status-There is an opportunity for the UK medical and nursing councils and the royal colleges to support their Indian counterparts in facilitating increased recognition and professional status for primary care in India, including introduction of accreditation and continuing professional development.

Affordable technologies-This is a strong opportunity for two way benefit. NICE International, the international arm of the UK's National Institute for Health and Clinical Excellence, can provide evidence about the affordability of care, including the cost effectiveness of drugs, vaccines, and other medical technologies. Indian IT and diagnostic companies can develop and produce innovative affordable technologies for primary care. UK university expertise in evaluating such technologies means the UK could be a test bed for such technological solutions, particularly to support patient self care.

Public-private partnership-The NHS has always commissioned its primary care from independent contractors, recently not only from NHS general practitioners but also from social enterprises and commercial providers. India has also introduced some very innovative PPP initiatives in the past five years. There is scope for mutual learning about healthcare commissioning as well as partnership in innovative service provision.

Healthcare governance-There is potential for partnerships, both public and commercial, to enhance governance by supporting the development of clinical guidelines, generic drug formularies, quality standards and performance indicators.

Research, development and innovationThere is potential for R\&D partnerships in both the public and private sectors in many areas, including developing and evaluating new affordable technologies for primary care in terms of equipment, staffing solutions, and 
other interventions that could be scaled up, and evaluating different health financing models and insurance schemes.

\section{Suggested way forward}

We suggest the CEO group considers facilitating the following activities:

1. Development of a five year plan by the Government of India Ministry of Health and Family Welfare to ensure that all doctors working in primary care are trained and accredited in the specialty and have the necessary skills and competencies to deliver uniformly good quality care. We note that the Indian National Conference on Health Professions Education 2011 has made a similar recommendation, suggesting that the proposed new National Council on Human Resources for Health (NCHRH) should have responsibility for setting standards and accrediting medical education. The UK General Medical Council might be asked to provide support by sharing their experience with the Government of India and relevant bodies. The Indian Nursing Council (INC) may also wish to work with the UK Nursing and Midwifery Council in developing training and accreditation for enhanced nursing roles.

2. Development of a series of evidence based clinical guidelines by the government, professional associations, and healthcare professionals working together for the delivery of primary care in India, perhaps by establishing an India NICE portal, which states could use to set quality standards and underpin clinical governance.

3. Development of a primary care formulary of effective, low cost, generic drugs and vaccines to be made available through primary care; this would take advantage of ongoing efforts to improve the system for drug procurement and distribution.

4. National support for a small number of states that are interested in developing primary care with UK support to act as national exemplars in:

- (i) Developing a number of centres of excellence in primary care to increase leadership capacity and provide a new generation of primary care clinicians able to act as professional leaders, trainers, researchers, and university faculty members.

- (ii) Implementing and evaluating innovative public-private partnership initiatives focusing on providing care to meet both millennium development goal (MDG) targets and the increasing challenge of chronic illness.

It is further suggested that each participating state appoints a small functional India-UK team to oversee the development, with responsibility to set strategic and operational objectives, engage with all relevant stakeholders, and exploit the opportunities for partnership outlined in this document.

5. Support to incentivise institutional collaboration and develop training awards to take forward partnership opportunities identified in education, staff training, and primary care R\&D. Priorities for partnership might include the development and evaluation of (i) affordable technologies to improve diagnosis and promote self-care; (ii) innovative training and governance solutions to improve the use of cheap effective medicines for chronic care; (iii) innovative outcome-based PPP commissioning to improve the care quality of existing primary care providers; (iv) application of new information technology to support provision of high quality care in remote areas without doctors; and (v) evaluation of different health financing models and insurance schemes.

6. Initiation of a joint India-UK government collaboration to scope further the commercial opportunities and potential areas for collaboration in the primary healthcare sector outlined in this document, with a particular focus on e-health, primary care management systems, primary care pathways, diagnostics, and any other relevant areas in the primary care value chain (the chain of activities involved in delivering cost effective primary healthcare).

\section{Background}

The Indian government launched the National Rural Health Mission (NRHM) in 2005 to "address infirmities and problems across primary health care and bring about improvement in the health system and the health status of those who live in the rural areas." A core strategy was to strengthen the existing primary health centres (PHCs) and community health centres (CHCs) in terms of both infrastructure and human resources, with a view to achieving a number of goals to reduce infant and maternal mortality as well as the incidence of several communicable diseases. ${ }^{1}$

A National Urban Health Mission was also intended to be established, to meet the needs of the urban poor, but was not implemented dur- ing the period of the 11th five year plan. The health mission plans recognised the importance of primary care as a means to improving access to healthcare. Furthermore, they also recognised that accelerated progress towards the health related millennium development goals would be facilitated by strengthening primary care services across the country. The 12th five year plan (2012-17) is expected to highlight strong primary care as a means to achieving universal access to good quality health care. $^{2}$

The recently released report from India's high level expert group on universal health coverage endorses this strategy and proposes a major role for primary healthcare in its national health package. It envisages high quality primary care provided free at the point of delivery and including the provision of free essential medicines.

The opportunity for partnership with the UK arises because primary care has been a central feature of the UK NHS since its inception. Although it is more medically focused than originally envisaged in the Alma Ata declaration on primary health care it has a number of features which make it consistent with some of its core values and relevant to the Indian situation. For example, most NHS care, including preventive care and management of chronic disease as well as first contact acute care, is delivered in a community setting to a good standard with universal coverage. It is provided by multidisciplinary clinical teams, mostly led by general practitioners (GPs) using affordable and appropriate technologies. In addition there is a strong focus on improving health outcomes-for example, remuneration is linked to patient outcomes. Outcomes are monitored in electronic clinical records against evidence based quality standards. ${ }^{3}$

The world leading strength of the IT, medical technology, and generic pharmaceutical industries in India provide an important strategic advantage for developing primary care that could be exploited in partnership with UK companies and institutions with primary care knowledge. UK primary care would also benefit from the development of new cost efficient technologies by Indian companies.

\section{What is primary healthcare?}

Starfield was the first to show by international comparison that primary healthcare was a central feature of all national health care systems delivering high quality care at affordable cost. ${ }^{4}$ She described it as "the provision of first contact, person-focused, ongoing care over time that meets the health-related needs of people, referring [to hospital] only those problems too 
uncommon to maintain competence." She also drew attention to the fact that primary care in cost efficient health systems "coordinates care when people receive services at other levels of care." ${ }^{5}$

The World Health Organisation (WHO) extends the definition of primary health care by placing great emphasis on local community involvement. It not only emphasises the importance of delivering care locally, without requiring people to travel long distances but also stresses the value of community development, teamwork, patient centred care, good local governance, and empowerment of people to take responsibility for their own health. WHO strongly endorses the primary care principles enshrined in the 1978 Alma Ata declaration, which are equity, intersectoral collaboration, access to essential drugs, appropriate health technology, and comprehensive care. ${ }^{6}$

The most recent international example of successful implementation of primary health care is the Brazil Family Health Programme. This large and diverse country has managed to achieve its MDG health targets through introduction of a team based primary care system which, adjusting for changes in other health determinants, reduced the infant mortality rate by $4.5 \%$ for every $10 \%$ step increase in population coverage. ${ }^{7}$ Recently there is also evidence of improved chronic disease outcomes.

The three elements of primary care that are most important in improving health outcomes and reducing the cost of a national health system with universal access are:

- Preventive care (such as vaccination, antenatal care, and measuring blood pressure)

- Care of chronic disease (all but the most acute phases of chronic illness can be managed effectively outside hospital; good community based care prevents clinical deterioration and the consequent need for episodes of hospital care)

- Diagnostic triage and control of hospital referral (most acute illness can also be managed effectively in the community; effective primary care sorts the serious from the non-serious by speedy and accurate diagnosis, directs hospital referrals to the most appropriate speciality, and ensures that expensive hospital resources are expended on those who will benefit most).

These three elements all require close liaison with hospital specialists and other healthcare disciplines so primary care has an important role in co-ordinating care across health sectors.

There is no "one size fits all" for delivering primary care, but effective teamwork and local ownership are common features of successful systems. This is achieved in the UK by commissioning primary care from multidisciplinary clinical teams led by GPs working as independent contractors for profit. These teams enjoy substantial organisational and professional freedom as long as the health outcomes meet national standards. Public satisfaction with each primary care centre in the UK is also monitored regularly and tends to be extremely high. ${ }^{8}$ This high satisfaction in part reflects the fact that the service is partly demand led-in most urban parts of the UK there is more than one NHS primary care centre in a geographical area and people are free to choose with which they register.

General practice is a popular specialty in its own right in the UK, and GPs have to undergo a rigorous postgraduate training programme involving hospital and primary care training. Once trained, they have to participate in regular continuing professional development (CPD) and annual assessment to be allowed to continue to practise.

For the past five years the UK government has also experimented with other public-private funding arrangements including private finance initiatives for primary care premises and commissioning a range of services from independent contractors. The primary care services commissioned go beyond traditional GP led general practice and include examples of patients being supported by advanced nurse practitioners working alongside therapists and social care partners to increase patients' ability to self-manage outside hospital. The chief executive of one successful social enterprise told us that co-ownership engenders both entrepreneurial teamwork and a feeling of common responsibility which is often absent from traditionally managed public enterprises. ${ }^{9}$

The optimal composition of a primary healthcare team will depend on local service priorities but also the local availability and competence of individual staff groups. There is a substantial international literature on the potential for role substitution, particularly nurses taking on roles traditionally done by doctors. ${ }^{10}$ In the UK, most primary care nurses have an enhanced role, providing both acute and chronic care, undertaking common procedures, and prescribing when appropriate, as well as providing preventive care. However, effective and safe diagnostic triage and gate keeping is a particularly high level clinical skill requiring access to diagnostic facilities, good decision support, and specialised postgraduate training; in the UK the task is still undertaken primarily by the doctors within the team.

A common weakness of primary care, deriving in part from its necessary diversity, is geo- graphical variation in care quality. Quality is often inversely correlated with need-often characterised as the "inverse care law." ${ }^{\text {"11 }}$ A key underlying problem causing inverse care within countries is the difficulty in recruiting and retaining high quality staff to work in disadvantaged areas. In the UK this variation in quality persists but has been reduced by ensuring there is no negative differential in pay or clinical facilities for clinicians working in disadvantaged areas and by continually assessing care outcomes against evidence based national standards.

In the UK, access to primary care is universal and free. A small charge is made for medicines but remitted for disadvantaged groups (for example, children, people on low income, and people who are chronically ill or elderly). The international literature shows that user fees stop the most impoverished groups from accessing care, but removing fees may have unintended consequences and actually reduce care quality if it impacts significantly on available funding for the service. ${ }^{12}$

\section{Primary healthcare in India}

Primary healthcare in India is very diverseboth public sector and private (not for profit and for profit) and provided by a variety of healthcare workers including "allopathic" doctors trained in UK style medicine, practitioners trained in the indigenous systems of medicine (ayurveda, unani, siddha, and homeopathic medicine-AYUSH), and traditional healers delivering care without any form of training.

There are major differences between states in urbanisation, economic resources, availability of healthcare workers, and primary care related health outcomes. For example, in 2009, Kerala had an infant mortality rate of 12/1000 and a supply of locally well trained nurses to staff their primary care facilities while Bihar had an infant mortality rate of 51/1000 and no nurse training facility.

The variation in progress towards the MDG targets despite significant public investment in health is at least partly attributed to the overall low quality and achievement of the primary care system in some parts of the country. This is compounded by poor access-primary care may not be provided free of charge even in public facilities ${ }^{13}$ and many people cannot afford to pay for care.

The flagship in the public sector is the government funded National Rural Health Mission (NRHM). Care is delivered by a three tier structure with subcentres at the level of the Gram Panchayat (5-6 villages), primary health centres (PHCs) for 30-40 villages, and community health centres (CHCs) serving about 100 
villages. The $\mathrm{CHCs}$ are polyclinic style, staffed by hospital specialists with about 30 inpatient beds and radiography facilities.

The NRHM integrates AYUSH practitioners into the PHCs to "optimise the utilization of these resources to meet the needs of the population as well as to reflect the growing interest in integrative care." However, the planning commission in its mid-term appraisal of the 10th five year plan in 2005 reported that, in general, there was much room for improvement of the quality of care in rural areas, whilst noting that there were some exceptions..$^{14}$

Continuing efforts are being made to improve service provision under the NRHM, and in 2009, $75 \%$ patient satisfaction was reported in Andhra Pradesh, but satisfaction with the service remained unacceptably low in the other three states surveyed (Uttar Pradesh 49\%, Rajasthan $39 \%$, Bihar 23\%). ${ }^{15}$

The 2010 NRHM review draws attention to the range of different organisations providing primary care in different states, including occupation related services (such as the Indian Railways and the Central Government Health Scheme) and non-governmental organisations (NGOs) from which the NRHM sometimes commissions primary care. ${ }^{16}$

The impact of the primary healthcare provided by the NGO sector to vulnerable groups is probably greater than its share of total health spend (about $0.3 \%$ ). It is not possible to cite here all examples of such care, although the impressive effect of some NGO partnered programmes has been shown formally in clinical trials. ${ }^{17}$

The 2010 NRHM review also drew attention to the problem of poor availability of essential medicines in primary care and to the common practice of prescribing expensive branded drugs to generate income for the prescriber and pharmacist. ${ }^{18}$ It recommended drawing up a formulary of cheap effective drugs and auditing compliance.

The vertical programmes which aim to deal with one specific disease (such as HIV, malaria, tuberculosis, polio) are often well resourced and deliver good care in a community setting. However, the challenge is to integrate this currently fragmented care within a wider primary care service without diverting scarce manpower resources from it. A recent WHO report documents a child receiving world class preventive care from a polio eradication clinic but his mother then having to take him to an unqualified health worker in an adjacent shop for diagnosis and treatment of his feverish illness. ${ }^{19}$

In urban areas, the diagnostic and curative aspects of primary care are provided for those who can pay by private hospitals and clinics. These are usually staffed by doctors without formal primary care training (and often any regulation), although they may have hospital training in disciplines relevant to primary care (such as general medicine, paediatrics, obstetrics, or mental health).

Some of the larger hospital groups provide first contact diagnostic and curative care to a high regulated standard on the polyclinic model; their performance of the other primary care functions of prevention, ongoing care of chronic disease, and gate-keeping is not reported.

In both the urban and rural sectors, there are a substantial number of informal private providers, including religious healers, who may or may not have any formal qualification and sell care of very variable quality. ${ }^{20}$ However, the availability, accessibility, community standing, confidentiality, and respectful attitude of the informal providers are reported to be much better than that of many trained public sector providers-and these are features which underpin the high public satisfaction with UK primary care. ${ }^{21}$ We are also aware of (as yet unpublished) evidence that in some areas untrained informal providers are giving higher quality clinical care than the trained public sector doctors.

India is unusual in the high proportion (70$80 \%$ ) of healthcare expenditure which is borne "out of pocket" by the individual, and most of this is spent on outpatient treatment, mainly medicines. ${ }^{14}$ Illness is therefore a common reason for families to be forced into poverty. Probably $10 \%$ of the population are covered by private health insurance, but policies do not extend to primary health care. A CEO of a private insurer explained to us that this was primarily because both the public and the insurers felt that primary care was of too poor quality and too unregulated to be included in cover. There is also a high transaction cost and moral hazard to funding high volume primary care activity through any claim-by-episode insurance scheme.

\section{The problems that need to be solved to strengthen primary care}

The Indian government is not only committed to strengthening primary care but is already well aware of the means to achieving this goal. Expert committees in India have made a number of cogent recommendations, many of which have received government support. As would be the case in any country, implementation of recommendations has been variable (in part dependent on the availability of resources and the political imperatives in different states), and some initiatives have been more successful than others.

The most successful primary care systems encourage decentralised planning to encourage local ownership and responsiveness to local circumstance. The only structural principle that seems to be invariable is the need for multidisciplinary teamwork. However, international experience suggests that whatever structure is chosen, there are a number of operational issues that need to be addressed to ensure that primary care is delivered effectively by that structure.

Five important operational problems in implementing effective care can be distilled from both the 2007 WHO India Health Workforce Report and the recent Lancet India series underpinning the call for the provision of universal health care coverage by $2020 .^{1922}$ These problems are:

- Inadequate human resources to staff primary care, evidenced by limited ability to recruit and retain high quality staff, particularly in disadvantaged areas

- Failure to deliver universally the key primary care services necessary to reach MDG targets (vaccination, nutrition and hygiene support, safe maternity services, effective first contact acute care for serious disease)

- Failure to deliver effectively the primary care services which reduce health system costs (prevention and care of chronic diseases, effective diagnosis and prioritisation for hospital referral)

- Lack of public and clinical governance of performance

- Poor leadership, public regard, and professional status.

Underlying these problems are three operational problems common to primary care in many countries and already recognised by the Indian government. These need to be separately recognised as issues needing solutions applied across all health sectors, but in this context they are discussed only in relation to solving the above primary care delivery problems:

- Funding models that are unresponsive to the value of high quality acute, preventive, and chronic care outside hospital

- Distribution and financing mechanisms for medicines that do not take advantage of the availability of cheap and effective generic medicines and fail to ensure such treatments are effectively distributed and universally available for common serious acute diseases (such as malaria and pneumonia) or common chronic diseases (such as asthma and hypertension)

- Lack of effective information systems, including failure to exploit the opportunities for patient involvement in self care inherent in modern information technology The National Conference on Health Professions Education 2011 in Vellore recently drew attention to the role of the current medical education system in contributing to "widening disparities in India in health status and access 


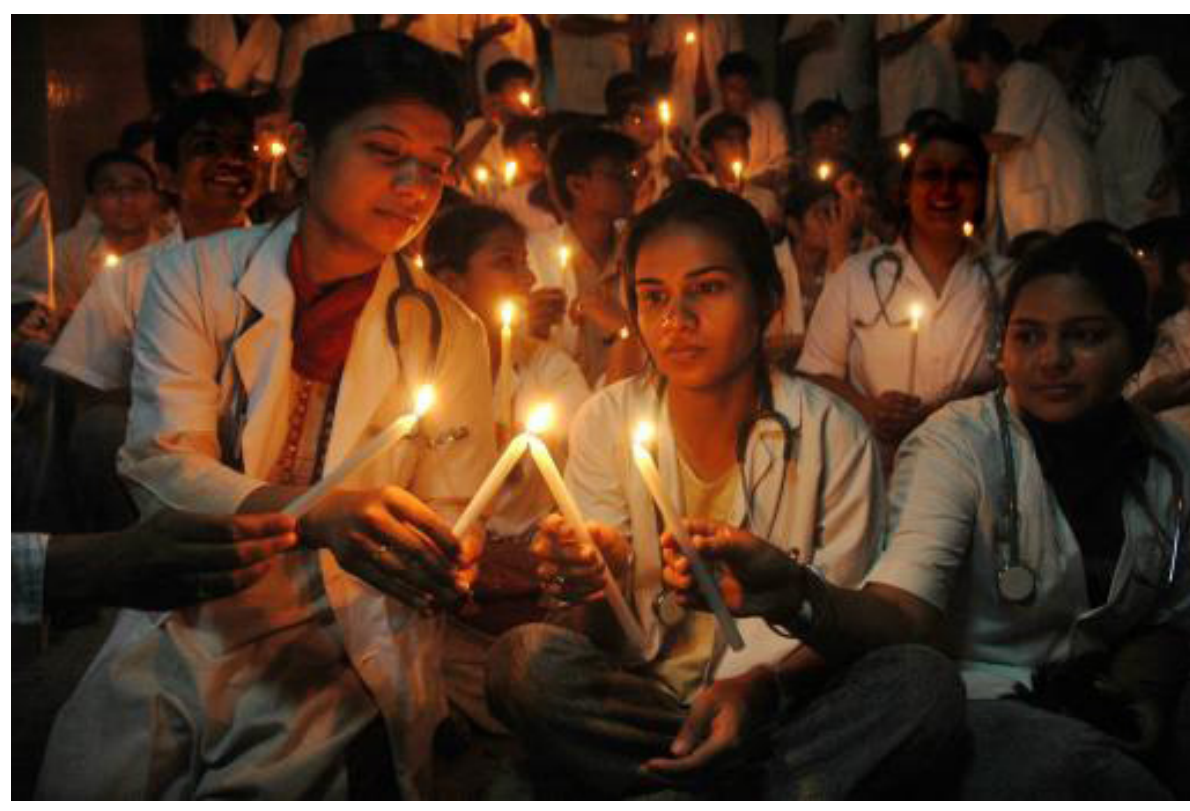

Fig 1| Medical students pay high fees for private education and many need to regain their investment

to basic health care" (fig 1). It concluded that: "The medical education does not prepare the graduate to function effectively in areas of need. Students who have paid high fees for private medical education prefer to pursue careers where they are able to regain their investment. As a result, there is the problem of wide scale foreign migration of medical graduates. Without the benefit of strong motivation imparted in their formative years, doctors are not inclined to work in rural locations and in difficult circumstances characterised by lack of adequate remuneration, difficulties in school education for children and academic and social isolation. Medical colleges are not linked to and responsible for the health system (at the district and sub-district level) and for the health of a community in a geographical area. Thus, responsibility for the health of the community is not manifestly linked with medical education." Although the statement focused largely on education of doctors, it was made clear that the conclusions also applied to education of nurses and other health professionals . ${ }^{23}$

\section{Strengthening human resources for primary} care

\subsection{Summary of problem}

Primary care is an extremely unattractive career for allopathic doctors with virtually no community based postgraduate training (nor accreditation of general practice as a speciality) and poor career prospects. The small number who have gained formal qualifications-Diploma of the National Board (Family Medicine) and Membership of the Royal College of General Practitioners (International)- remain unrecognised and disenfranchised. The public and professional status of the few doctors working in primary care in India is therefore low. Both pay and working conditions tend to be poor in comparison to hospital practice.

In 2010, according to the approach paper for the 12 th five year plan, $10 \%$ of posts for doctors at the PHCs and $63 \%$ of the specialist posts at the CHCs, and $25 \%$ of the nursing posts at PHCs and CHCs combined remained unfilled. The situation for support staff is similar with $27 \%$ of pharmacist and $50 \%$ of laboratory technician posts also vacant. ${ }^{2}$

The quality of the medical staff in primary care is poor. A 2007 World Bank investigation of healthcare in Delhi reported that doctors in primary care centres had less competence and made less effort than staff in the hospital

\subsection{Platforms to build on}

bonds to enhance recruitment of good doctors to rural areas. ${ }^{19} 20$ family medicine departments in every medical college. ${ }^{23}$ training and quality. sector, particularly the private hospital sector. $^{24}$

There is little evidence of effective manpower planning or effective training for primary care, either to use the available human resources (medical officers, nurses, AYUSH practitioners) more effectively in the short term or to deliver a trained multidisciplinary workforce (of a composition customised to meet local needs) in the longer term.

\subsection{Strategic points}

The 2007 WHO report on the health workforce in India characterised the manpower problem as not an absolute lack but "not enough here...too many there." ${ }^{19}$ The report also suggests that AYUSH practitioners and other informal providers could be trained and used to staff primary care facilities in a "bolder and more efficient way."

The 2011 Lancet paper on human resources concluded that "India has to move away from the idea that only allopathic doctors can deliver primary care." ${ }^{20}$ There is great potential for effective role substitution in primary care. ${ }^{10}$ However, effective diagnostic triage (gatekeeping) requires the high level clinical skills and ability to assess and manage risk which doctors specifically are trained to undertake.

Primary care is best delivered by multiprofessional teamwork. A number of strategies have been shown to enhance teamwork. ${ }^{26}$ Multiskilling (training individuals to perform tasks within their capacity but beyond their traditional professional roles) allows the available workforce in the team to be deployed most efficiently. ${ }^{27}$

There is good international evidence on the efficacy of different strategies to improve recruitment and retention of health workers

Some states (for example, Tamil Nadu, Kerala, Gujarat, Andhra Pradesh, Meghalaya, Haryana, West Bengal, and Assam) have introduced incentive schemes-monetary and non-monetary-and compulsory service

The National Committee on Macroeconomics and Health (NCMH) have recommended developing clinical and management skills in nurses and utilising their capacity beyond their existing roles. At least one state

(Orissa) has already established a partnership with a UK nursing school to enhance nurse training.

The NRHM has put in place initiatives to develop specialist clinical skills in non-medical practitioners to bridge current gaps in provision; this includes appointing more female community health workers and supporting training of a cadre of medical practitioners (studying for a shorter bachelor of rural medicine and surgery degree) who will not be accredited to work outside rural primary care. ${ }^{25}$

The 2011 National Conference on Health Profession Education concluding statement outlined a number of steps to develop capacity in family medicine and strengthen training pathways, including establishing

Several medical colleges are offering postgraduate training in primary care for allopathic doctors, including higher qualifications in family medicine (DNB (FM)), with some courses now being sponsored by state governments (for example, Bihar, Andhra Pradesh, West Bengal).

There are at least two professional organisations (the Academy of Family Physicians of India and the College of General Practitioners of the Indian Medical Association) with a mission to improve primary care 


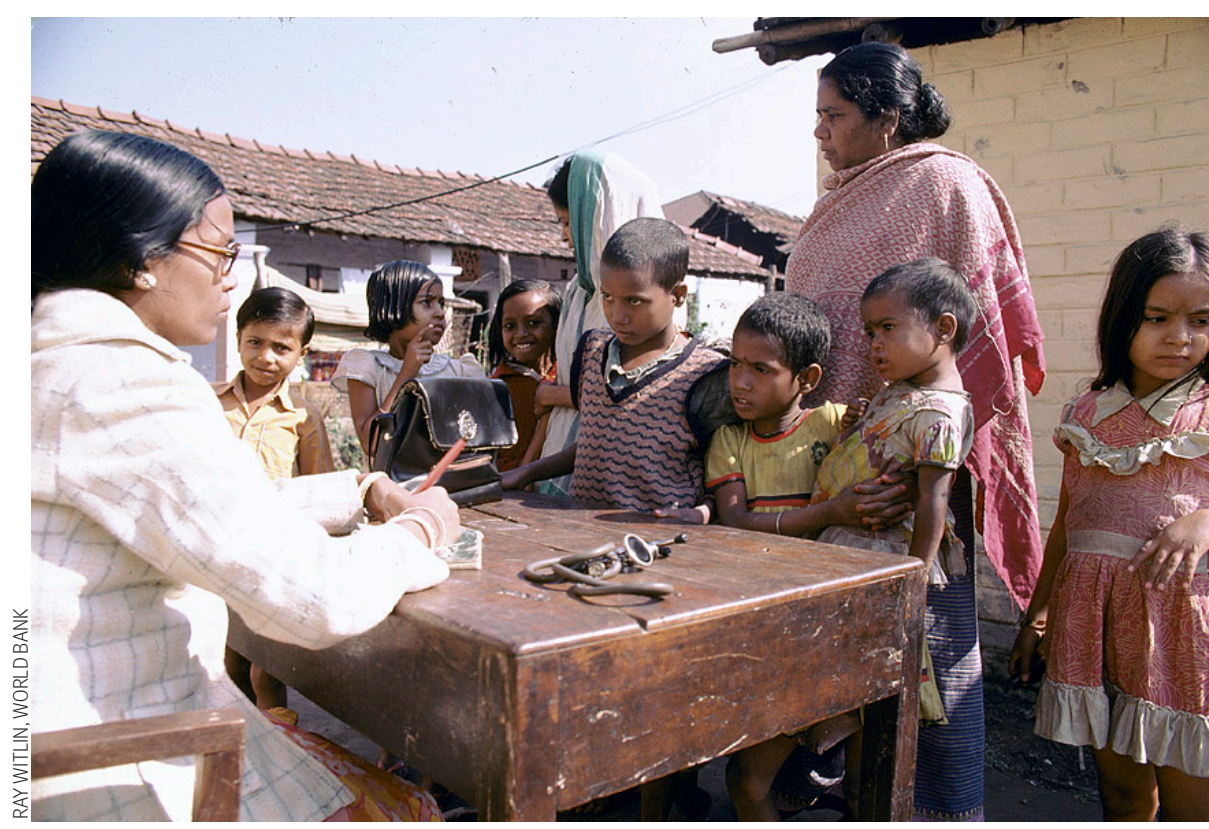

Fig 2 |Clinicians in underserved areas should enjoy preference for postgraduate training

\subsection{Opportunities for partnership}

Training and professional support for nurses and other staff in primary care teams wishing to develop enhanced specialist roles could be developed by partnership between professional bodies, Universities, and private educational providers. Specific areas of reported need which could be met include emergency medicine, child health, orthopaedics and wound care, antenatal care that combines attention to health and nutrition and management of non-communicable diseases.

Similar partnership opportunities exist to support the training, accreditation and continuing professional development of primary care specialist doctors. The UK Royal College of General Practitioners (RCGP) has already established links with the College of General Practitioners of the Indian Medical Association and with government departments in some states. A number of commercial publishing companies in the UK specialise in providing educational material for general practitioners, including digital material and on-line decision support, which could (with appropriate partnership) be adapted for an Indian market.

Other disciplines that might benefit from UK support in delivering enhanced skills training include physiotherapists, dieticians, paramedics and therapists.

The potential to involve the high quality, hospital based polyclinics in delivering primary care training needs to be explored, with UK primary care support if necessary. For example, a recently launched scheme to deliver primary care in urban areas utilising role enhanced nurse practitioners (supported by UK trainers) may also provide a helpful local training environment.

in rural and disadvantaged areas, of which some states appear already to be aware. ${ }^{20}$ Brazil, which managed to recruit doctors to lead the primary care centres in the Family Medicine Programme, paid salaries that were high by local standards. However, non-monetary incentives such as provision of autonomy, plus good working and living conditions are also effective-as is, in the longer term, prioritising recruitment of trainees from those living in underserved areas. ${ }^{28}$

There are a number of international examples of the use of new technology ("telemedicine") to improve outreach to remote areas. In India, there is an obvious opportunity to exploit new technologies to provide clinical support (and governance) for community health workers living and working in hard to reach rural areas through electronic links to multidisciplinary teams based in a larger conurbation. Support could include guidance on diagnosis, prescribing, and onward referral.

Introduction of specialist recognition, with accreditation and mandatory continuing professional medical education (CME) and appraisal, is an essential first step to developing a clinical workforce with the necessary knowledge and skills to provide an adequate quality of primary care.

The National Conference on Health Professions Education 2011 suggested that, because of the shortage of senior trained staff in primary care with any academic training, "in the initial period Family Medicine Departments may be staffed by faculty from the general specialties until there are sufficient numbers of trained family physicians."23

The conference also recommended:

- Preference for admission to education and training courses for doctors and nurses should be given to local students from rural and underserved areas

- Clinicians working in underserved areas should enjoy preference for postgraduate training, financial incentives, communication facilities, and opportunities for education of their children

- Compulsory service in underserved areas by all medical graduates should be reintroduced (fig 2 ). ${ }^{23}$

\section{Strengthening capacity to deliver universal services important for MDG targets}

\subsection{Summary of problem}

There is a major difference in MDG health indicators between urban and rural areas and between states, with many states showing excellent progress towards the goals, and others where the pace of change is much slower. For example, the national target for infant mortality is $<30 / 1000$; the projected rate in 2015 is $31 / 1000$ in urban areas but $43 / 1000$ in rural areas.

The projected infant mortality rate between states varies 12 -fold, from 5/1000 in Goa to 58/1000 in Madhya Pradesh and Meghalaya. Apart from Goa, only Kerala, Maharashtra, Tamil Nadu and West Bengal are projected to hit the national target. One suggested explanation is that "coverage for priority interventions remains insufficient and quality of existing programmes sub-optimum." ${ }^{29}$

India is also off- track to meeting its declared national and MDG targets for child mortality. The child mortality rate age <5 years was 63/1000 live births in 2010 (MDG target 38 ). The maternal mortality ratio was 254/100 000 live births in 2004-6 (MDG target $<100)$. The prevalence of underweight children was 43\% in 2005-6 (MDG target $27 \%$ ). This suggests there are 1.8 million child deaths and 68000 maternal deaths in India each year and 52 million undernourished children.

Important avoidable factors in child deaths, directly attributable to poor primary care, are failure to vaccinate and treat the common childhood infections effectively. Child immunisation coverage in India is reported to be only $54 \%$ (children fully vaccinated for measles, polio, tetanus, diphtheria, pertussis, and tuberculosis in 2007-8) and use of simple life saving treatment such as oral rehydration for diarrhoea unacceptably low (34\%). ${ }^{30}$ Poor supply and distribution of vaccines, including cold chain failures, are reported to be common despite India being a major vaccine producer. 


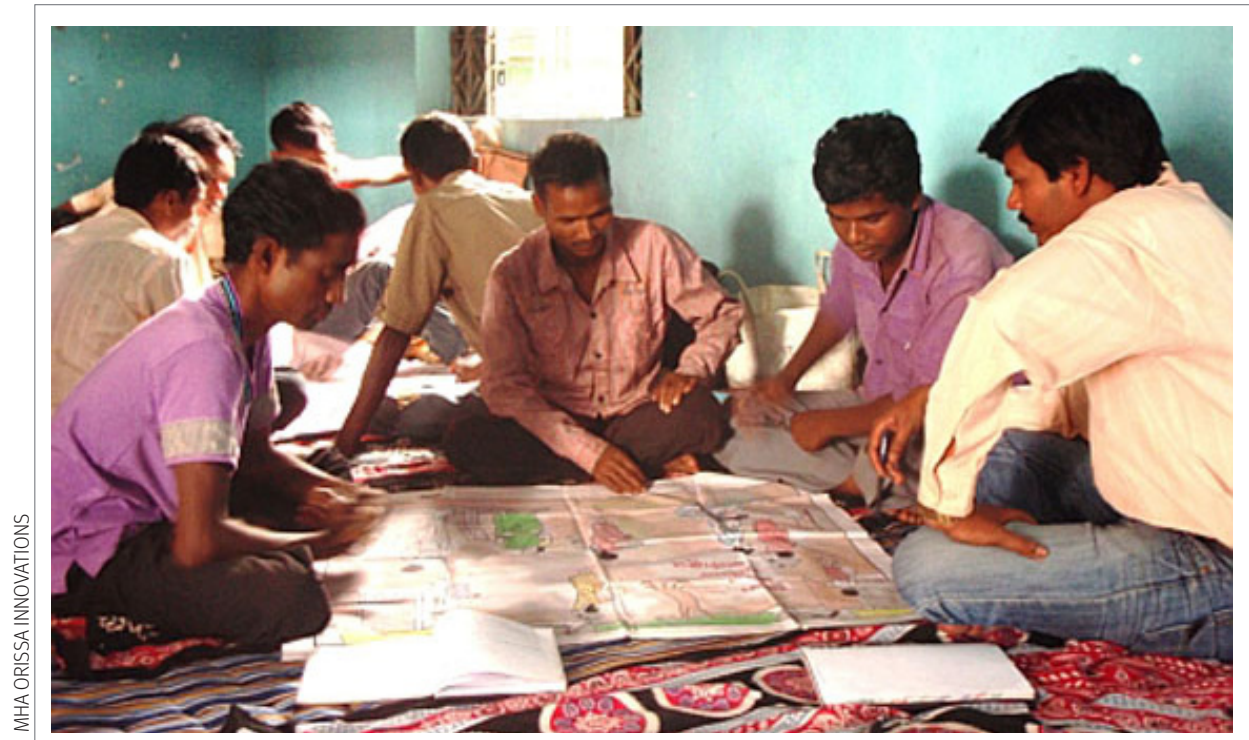

Fig $3 \mid$ Community health workers in Orissa

\subsection{Platforms to build on}

The National Rural Health Mission (NRHM) is a great testament to the determination of the Indian government to deliver universal primary health care and it has had impact-for example, maternal mortality fell by $36 \%$ between $1997-8$ and $2004-6{ }^{31}$ This success needs to be built on to eliminate major regional differences in the staffing and performance of primary care. $^{32}$

The NRHM has been innovative and effective in some of its community development activitiesemploying social health activists and auxiliary midwives, establishing local sanitation committees, and organising emergency transport systems (operational in 12 states).

The Janani Suraksha Yojana (a cash transfer programme to encourage institutional delivery) has increased births in rural health facilities from $30 \%$ to $38 \%$, although it is not clear that this has improved the quality of antenatal care and the quality of intrapartum care received is often inadequate. ${ }^{33}$

There is good evidence of innovative approaches to obstetric care that have reduced maternal mortality by building effective local teams integrating primary and hospital care. These teams ensure that women have access to high quality antenatal care as well as increasing the number of births taking place in a safe environment. ${ }^{17} 34$

The WHO/Unicef inspired integrated management of neonatal childhood illnesses strategy had been initiated in 223 (of 643) districts by June 2009. The UK's Department for International Development (DFID) has existing MoUs with the Indian government at the national level through the Ministry of External Affairs and with three states (Bihar, Orissa, and Madhya Pradesh) and has consistently given a high priority to programmes aimed at strengthening services for improving maternal and child health.

\subsection{Strategic points}

The Brazilian Family Health Programme, which has been very effective in achieving MDG health targets in a large and diverse middle income country, was based on establishment of com- munity health units each serving $<5000$ people and staffed by multidisciplinary teams (doctor, nurse, auxiliary nurse midwife, 4-6 community health workers) operating on a decentralised community development model. The programme provided care for about 85 million people and the cost was between $£ 20$ and $£ 32$ per capita per year. ${ }^{35}$

There are good examples of this Brazilian style community development approach to primary care being applied successfully in India-for example, in Jharkhand and Orissa, employment of community health workers to (a) support participatory action and learning for women and $(b)$ facilitate the development and implementation of strategies to address maternal and newborn health problems, reduced the neonatal mortality rate by $32 \%$ (fig 3 ). ${ }^{36}$

The urban poor need particular attentionalthough MDG health indicators are still consistently worse in rural than urban areas, they differ much less between the rural and urban poor. $^{37}$

There is strong evidence that community child health workers can improve vaccine uptake and breast feeding and some evidence that they can reduce infant and child mortality, especially through case management. ${ }^{38} 39$

Child and maternal mortality are closely linked to nutritional status. There seems to be an unmet need for integrated nutritional and health advice-for children, pregnant women, and adults-as well as universal access to effective family planning services. The existing Anganwadi child development (ICD) programme has not impacted on the nutritional status of children. ${ }^{29}$ Improving the evidence base for delivering such care (for example, to allow an evidence based decision on the most important target age group) may help.

\subsection{Opportunities for partnership}

DFID supported specialist technical advisory teams (TASTs) already working in a number of states are a good model for the provision of expert support drawing on UK and Indian expertise and development of local capacity and sustainability. As the NHS primary care system model is based on commissioning care from local independent multidisciplinary teams, UK organisations (NHS Global, commercial health consultancies, universities) can also support and advise on implementation of a devolved model of care, where appropriate working with TASTs

The UK NHS has a strong system for providing effective preventive care, including a national primary care delivered vaccine programme supported by an electronic management system. Opportunities exist for partnership in both staff training and supporting the development and implementation of effective IT based screening and vaccine management programmes

Early recognition of the acutely ill child in community settings can be improved by the use of modern technology, both in measuring vital signs and by better involving the parent. This can be at a system level (such as the NHS Direct telephone help line, which has already inspired the 104 service in Andhra Pradesh) or an individual level (using the mobile telephone simply as a means of communication with the parent or for distance monitoring). There is strong potential for R\&D partnership with the IT and health technology sector in India to develop innovative affordable technologies with very wide scale application

There is much that the UK can gain from such partnership. Although the scale of the challenges may be different, the UK too has persistent health and social inequalities and needs to explore how innovative models developed in India may be adapted to improve the health of its most deprived and hard to reach communities.

\section{Strengthening capacity to deliver services which reduce system cost} 7.1 Summary of problem

Chronic diseases (such as heart disease, diabetes, cancer, and mental ill health) are already the leading cause of death and disability in India, and they will consume an ever increasing proportion of the health budget. Much of the care for chronic disease in India is currently provided by the private sector and can be very expensive.

A substantial proportion of the population receive no treatment ( $47 \%$ of diabetics and $91 \%$ of those with angina in one survey). ${ }^{40}$ The availability of preventive care is also very restricted with low coverage, particularly in poor and rural populations, further increasing the growing burden of disease. Lack of any opportunity for systematic or opportunistic screening at a primary care level means that chronic disease is usually detected at a late stage (when the disease is quite advanced and treatment both less effective and more expensive). 
The lack of a strong primary care function also means that diagnostic triage for both acute and chronic disease is usually conducted by hospital based doctors; this often leads to high levels of investigation, use of more expensive non-generic medicines, and the potential for inappropriate management by someone working outside their area of specialist expertise.

As already stated above, cost effective generic medicines are not always available in primary care; nor are they routinely used when they are available.

\subsection{Platforms to build on}

The care of chronic disease offered by some of the large hospital groups is not cheap but is reported to be of high quality, to an international standard, and includes preventive care. The polyclinic-style outpatient facilities also offer diagnostic triage of a quality that does not appear to be available in public facilities.

A number of exemplar chronic disease management projects have been launched successfully in some states. For example in Tamil Nadu, the Chunampet rural diabetes prevention project has screened $90 \%$ of the population of 25000 adults and is reported to have reduced mean $\mathrm{HbA1}$ c from 9.3 to $8.5 \%{ }^{41}$ Telemedicine technology is used to screen for complications such as retinopathy.

A national programme to reduce risk and promote early diagnosis of diabetes, cardiovascular disease, and stroke was established as a pilot project in 10 states in 2008 and is now being rolled out; this complements existing programmes in cancer control and mental health. However, multimorbidity is common in disadvantaged populations and a crucial role for primary care in any health system is to transform disease-specific vertical programmes.

\subsection{Strategic points}

India has a major advantage in dealing with its epidemic of chronic disease because its generic pharmaceutical companies produce high quality medicines at prices that are among the lowest in the world.

The UK has a national formulary (the British National Formulary) distributed free to all primary care clinicians through NHS Evidence. Many individual practices and local primary care trusts have their own agreed formulary of cost effective medicines for routine use. The proportion of medicines prescribed generically by each primary care centre is continuously monitored and used as a quality indicator linked to remuneration.

The most effective preventive strategies are dependent on legislation (for example, tobacco control and taxes), but primary care is very effective at delivering effective individual interventions at routine consultations to prevent heart disease, stroke, and cancer. ${ }^{42}$

Chronic illness (including serious problems

\subsection{Opportunities for partnership}

The chronic disease prevention and management programmes in UK general practice are greatly facilitated by computerised medical records and patient management systems, including expert decision support. There is potential for partnership between the UK companies providing these systems and Indian IT companies in developing India-specific applications. The introduction of unique identification and smart cards in India to facilitate access to health and other services, may facilitate the establishment of a population register based primary care service that can provide the full range of health promotion, preventive, and curative services to the population, as is the case in the UK.

A number of the PPP initiatives in the UK, including the employer owned social enterprises, have developed innovative care pathways for chronic care and achieved a level of staff motivation which might provide a helpful partnership opportunity for those states interested in developing similar initiatives.

UK primary care is effectively run as a franchise, with careful regulation of care quality. NHS Global should perhaps discuss with interested states the feasibility of developing an NHS in India franchise, offering primary care to carefully monitored and regulated quality standards provided by NHS trained staff from NHS badged health centres

The development of a national primary care formulary of effective low cost generic drugs needs local clinical involvement but may be helped by the involvement of independent external expertise to provide up-to-date evidence and reduce the risk of inappropriate commercial pressure. Both NICE International and the British National Formulary staff could provide such expertise.

There is growing use in the UK of mobile phone and other new technologies to empower patients to monitor and self-manage their illness (and increasing evidence that this is effective in reducing morbidity). There is strong potential for R\&D partnership between UK and Indian IT and health technology companies, perhaps supported by primary care departments in UK

such as diabetes, asthma, hypertension, arthritis, depression, and heart failure) is treated mainly in primary care in the UK and in many other countries. Specialist involvement can be restricted to treating complications of problematic cases without loss of care quality. Primary care can be as effective as hospital care if good liaison exists with the hospital specialist. ${ }^{43}$ Consistency of care quality can be assured by monitoring against national evidence based quality standards for diagnosis, prescribing and care outcome. ${ }^{44}$

Two recent randomised trials from India have shown that lay health workers in the community can also be very effective at managing chronic mental health problems (both anxiety and depression and dementia). ${ }^{45} 46$

Primary care can be a very effective mechanism to control healthcare costs while improving health outcomes (by primary care doctors making referral decisions on the basis of accurate diag-
Universities, to further develop these technologies for the mutual benefit of both countries.

There is also strong potential for Indian companies, alone or in partnership, to develop and test many of the technologies on the WHO-PEN list at low cost for application in primary care. In this circumstance, the UK may be a useful test bed for the Indian as well as the European market. It is likely that India will eventually leapfrog the UKin the use of new technologies in the management of chronic disease.

As stated in section 6 above, there is opportunity for commercial partnership with UK companies that have a strong track record in advising on health service development, planning and delivery, particularly issues of financing and governance.

The UK also has a strong cadre of primary care based advanced nurses specialising in chronic diseases (diabetes, heart failure, asthma, mental health, etc), as well as nurses and healthcare workers working at less specialised levels as part of a coherent multidisciplinary team. This has the additional benefit of providing a career framework which allows community development workers a route to become advanced nurse specialists with appropriate training and development. Such training and career frameworks can be developed for the Indian context, starting perhaps at the level of the ASHA worker (Accredited Social Health Activist) and ending with an advanced nurse practitioner. The opportunities for training partnership have already been mentioned in section 5 above.

The UK has a strong track record in the development of primary care guidelines and clinical pathways, including ones in electronic format (http://pathways. nice.org.uk// for underpinning decision support systems, with a focus on chronic disease management and for reducing unwanted variations in care.

Furthermore, the Quality and Outcomes Framework, the largest primary care pay-for-performance scheme in the world, has been operating in the NHS since 2004. These experiences can be shared as India develops its own primary care system to address its own needs.

noses and managing most patients in the community according to evidence based guidelines using generic drugs). ${ }^{47}$

The evidence for the effectiveness of the diagnostic triage/gatekeeping function comes from primary care systems staffed by doctors with postgraduate training in a community setting, specialist accreditation as general practitioners, and access to standard diagnostic facilities such as blood tests, ultrasound, and imaging.

There is growing evidence of the effectiveness of technology assisted self care (for example, selfmonitoring of blood pressure, blood coagulation (INR), and blood glucose) in reducing morbidity and mortality. ${ }^{48-50}$ Self-management of chronic illness also reduces healthcare workload and costs.

WHO has produced a list of important interventions for non-communicable disease in low resource settings (WHO PEN). It lists the following essential diagnostic and monitoring 
technologies it is important to have available at affordable cost: thermometer, stethoscope, blood pressure measurement device, measurement tape, weighing machine, peak flow meter, spacers for inhalers, glucometer, blood glucose test strips, urine protein test strips, urine ketones test strips, WHO/ISH risk prediction charts, evidence based clinical protocols, flow charts with referral criteria, patient clinical record, medical information register, and audit tools. It also adds, when resources permit: nebuliser, pulse oximeter, blood cholesterol assay, lipid profile test, serum creatinine assay, troponin test strips, urine microalbuminuria test strips, and electrocardiograph (if training or support to read and interpret electrocardiograms is available). ${ }^{51}$

Technologies for which there would be a large market in India, and from which the UK could also benefit, include refinements of established home monitoring devices for diabetes, blood pressure, and respiratory function testing (spirometry, oximetry) as well as new technological developments that would allow real time monitoring or screening for a range of other chronic diseases.

\section{Strengthening public and clinical governance 8.1 Summary of problem}

There are major variations between states in the efficacy of governance. The devolution of responsibility to local levels, including the provision of untied cash funds, has resulted in excellent results in terms of improving local services through collective ownership of problems and solutions in many cases. However, local governance arrangements may not always be effective, particularly if decisions are being made with limited knowledge of the evidence-base and the outcome of care is not being monitored effectively.

An Indian government audit report in 2008 concluded that poor quality services, wastage, corruption, and weak management still characterise many of the community based primary healthcare institutions. A particular problem in some rural primary care centres has been absentee workers ("ghosts")-with up to a 50\% absentee rate reported at spot checks in some areas. ${ }^{19}$

There is huge unexplained variation in care both within and between states. For example, major differences are documented between the public and private sectors and between differently qualified practitioners, in drug prescribing and frequency of surgical interventions (such as caesarean sections). ${ }^{52}$

The Medical Council of India and the other professional regulatory councils face a major task in implementing standards for both initial training and continuing professional development if they are to ensure that the clinicians responsible for providing primary care to the Indian population have the necessary knowledge, skills, and attitudes to deliver care of a consistently good standard. Not only does it appear that at present few clinicians are equipped to do this even if they hold a professional qualification, but a number of clinicians and nurses currently providing care are reported as not holding any valid professional qualifications at all. ${ }^{20}$

\subsection{Platforms to build on}

Most of the evidence of poor governance in the health services comes from effective internal investigation and inquiry to ensure that the challenges are well documented and understood.

While some elements of the public and private sector appear to lack any governance, other sectors report strong compliance with international standards in the public, private, and non-profit sectors.

Some states, such as Karnataka, have already instituted strong governance programmes based on community involvement and decentralised planning to which they attribute recent improvements in health outcomes. $^{53}$

\subsection{Strategic points}

In the UK, remuneration for primary care is based in part on assessment of performance against evidence based, nationally agreed quality standards. Adherence to these standards is assessed by central electronic interrogation of computerised patient records. All clinical activity undertaken in primary care facilities, including prescribing and recording of medical records, is now electronicas is the linked financial management system.

Public governance of general practice in the UK is achieved partly by creating a demand led situation-giving patients choice about the primary care provider with which they register so they can "vote with their feet." However, consumer satisfaction with primary care in the UK is also assessed by a nationally conducted annual survey in every primary care centre, which records patient views about service quality and ease of access.

At a district level in the UK, the financial and clinical performance of all primary care centres is overseen by an NHS trust directed by a board with governance responsibility and strong community representation.

There is little evidence in the international literature of which we are aware that electronic clinical support systems have been used effectively to improve clinical outcomes in primary care. However, the growing availability of fast response electronic technology (to both doctors and patients) suggests that electronic support for clinical decisions by doctors, plus IT supported self-care by patients, has strong potential to improve care quality in the future. Such clinical support systems also have the potential to improve clinical governance.

Some of the newly established health financing schemes established in states such as And- hra Pradesh (to improve the access of below poverty line families to secondary and tertiary care) are built on very strong innovative IT platforms aimed at ensuring clinical, financial, and administrative governance. Such systems could potentially be extended into primary care.

Each year every primary care clinician in the UK (not just doctors) is subject to an appraisal of performance. For general practitioners, this includes review of achievement of quality outcome standards (prescribing, vaccination rates, and indicators of good care such as levels of $\mathrm{HbA1c}$ in diabetic patients) and patient feedback (including any complaints). Obligatory CPD includes regular updating of key skills such as cardiac-pulmonary resuscitation as well as clinical knowledge in areas such as child protection. Satisfactory appraisal is a condition of continuing to practise (that is, of maintaining professional council registration and specialist accreditation).

\subsection{Opportunities for partnership}

The evidence based national quality standards in the UK are, to a large part, based on clinical guidelines developed by NICE. The international arm of NICE has already been engaging with different stakeholders at national and state level (as well as NGOs and commercial partners) in India. Although there is considerable experience and knowledge in the UK of the health of Indian populations, guidelines developed in the UK would need to be carefully adapted to the Indian context. There is considerable potential to strengthen the partnership with NICE to establish short guideline groups focused on the adaptation of (and development of new) existing guidelines, bringing together groups of clinicians and other stakeholders to carry out this task.

The ability to monitor centrally the ongoing performance of primary care in the UK is predicated on the electronic record systems installed in all NHS practices. These systems are provided (and supported) by commercial companies. In Indian states too, there are highly developed systems for administering health financing schemes, designed by government and commercial companies working together to translate the needs of health service commissioning into appropriate IT systems. There is potential for partnership between these UK companies and Indian IT providers to develop and provide operational support for using them in India and the UK.

The NHS and central and state governments in India have accumulated considerable experience in terms of what works (or does not work) in public-private partnership arrangements, particularly commissioning healthcare from private providers. NHS Global, the international outreach arm of the NHS, and a number of UK commercial consultancies and universities responsible for the evaluation of these schemes, are in a strong position to advise on what has and has not been successful in the UK. State governments with relevant experience would be well placed to lead Indian representation in a collaborative learning network to strengthen knowledge and competence in both countries. 


\section{Strengthening primary care leadership and status}

\subsection{Summary of problem}

Primary care is not yet recognised by the Medical Council of India (MCI) as a specialty, although MCI has advocated for the creation of a diploma course in family medicine.${ }^{54}$ Primary care practitioners therefore have no formal postgraduate training, no specialist accreditation, and no system for career progression. They have lower pay and worse working conditions than their hospital colleagues. Lack of appropriate training or qualification does not at present appear to be a barrier to employment as a primary care doctor. ${ }^{55}$

Although some states are beginning to introduce voluntary continuing education (CME) programmes for those working in primary care, this is neither compulsory nor universal, with no national guidance on the essential components.

The current primary care structure requires recruitment of doctors to posts in rural areas where housing, transport, school education, and facilities for personal healthcare may be poor. India is not alone in facing this problem, but only some states seem to have implemented successful solutions (despite international examples of what is, and is not, likely to be effective). An alternative option may be to test and adopt a system that delivers good quality primary care without a doctor on site; by linking well trained community workers on site through the innovative use of technology to a team of primary care doctors and nurses available at a more distant location.

Failure to recruit quality practitioners to primary care over many years means that there is no pool of well trained and motivated primary care practitioners to act as leaders and university faculty and train the next generation in order to reverse the situation.

There is also no tradition of primary care research, contributing further to low professional status as well as evidence-free, low quality clinical practice. This has also resulted in a lack of innovation in terms of exploring sustainable alternative ways to provide high quality primary care services.

Government of India has made funds available for five years to all government medical schools to create departments of family medicine yet these cannot start due to lack of suitably qualified individuals to staff them.

\subsection{Strategic points}

It is necessary to break the vicious circle of lack of high quality staff making it impossible to recruit faculty to train high quality staff. This means that the first steps to develop primary care must be taken in, and built around, places where high quality care already exists-the private and public hospitals known for their high quality care and the exemplar community projects.

\subsection{Platforms to build on}

As already stated, there are at least two professional organisations (the Academy of Family Physicians of India and the College of General Practitioners of the Indian Medical Association) with a mission to improve primary care training and quality.

Several research and training organisations, as well as non-governmental organisations involved in healthcare delivery, have been active in promoting the need for primary care and have the capacity to promote and provide training for delivering high quality primary care and to support research. However, these are few in number and therefore training capacity is very limited.

The high quality diagnostic and curative primary care offered by doctors working in major hospital outpatients and polyclinics is limited in scope and function but is a possible starting point with greater capacity to develop effective clinical services working to international quality standards.

Recently established family practice models (such as the Pathfinder Health India clinics and Nationwidedocs.org clinics) may evolve into a cohort of high quality community based primary care centres that could support training.

Increasing public support for primary care is important. The exemplar community based public services developed in some high performing states (for example, maternity care in Tamil Nadu inter alia) and a number of NGO supported community programmes are reported to have achieved high public status and may provide helpful seeds from which to grow more highly regarded public services in other places. An additional benefit from harnessing public support is to strengthen health literacy among the public and to refine people's expectations so that, for example, they begin to understand the risks of overmedication and overinvestigation, which are currently assumed to be better quality medical care.

The current high status of primary care in the UK has evolved over 50 years; key steps included the formation of a royal college, the introduction of mandatory postgraduate training and accreditation, the improvement of working conditions (including open access to hospital diagnostic facilities), and the move to equality of pay with hospital colleagues.

The growth of primary care led community based teaching in medical schools was heavily influenced by the requirements laid down by the UK GMC (the equivalent of the MCI). UK medical schools are regularly visited to assess training quality and any universities whose schools failed to deliver effective primary care training would be required to comply.

There is strong consensus in the UK that both primary care practice and primary care research is most effective if it is done with close collaboration between primary care and hospital clinicians. Most research papers in internationally leading academic journals providing evidence to support clinical practice in primary care are based on such collaboration.

\subsection{Opportunities for partnership}

The professional regulatory councils in India can do much to support the development of primary care. There is great potential for them to share experiences with their UK counterparts on how to promote the training and recognition of primary care practitioners. The UK GMC has already met with the MCI for an intensive joint learning week in April 2011, and to establish closer collaboration.

Many UK universities already have good links with Indian medical colleges, although it appears not yet in primary care. Links between nursing faculties are also limited. There is an opportunity to remedy this and provide greater support for the efforts of Indian medical and nursing colleges to establish academic departments of primary care. The leading Indian universities with research expertise could also partner with UK universities with primary care research expertise to evaluate new primary care initiatives, including exemplar projects, and provide the additional evidence necessary to help customise evidence based clinical guidelines to the Indian context.

It should be feasible, with appropriate partnership, to provide leadership training for primary care clinicians in India. For example, the UK NIHR National School for Primary Care Research runs international leadership workshops for academic general practitioners from Europe, North America, and Australia, setting up academic learning sets and offering mentoring for the brightest early career clinical academics. The UKR Royal College of Nursing also offers bespoke leadership training.

There is an opportunity for partnership in establishing national/state conferences on primary care as a regular tradition-for example, the UK RCGP recently partnered with the Indian college to run a national conference sponsored by a UK-India publishing company.

The Academy of Family Physicians of India is about to launch a Journal of Family Medicine and Primary Care. There may be potential to partner with a primary care focused UK journal (such as the British Journal of General Practice) or other medical publishers providing continuing medical education in different formats. There may also be an emerging market for a national "trade" magazine aimed at the service practitioners in primary care.

\section{Summary}

\subsection{Overall strategic analysis}

There is wide recognition that India's strategy for improving public health needs to give a high priority to strengthening primary care, but there is a lack of adequately trained primary care doctors. The challenge of providing uniformly good primary care in such a vast country can only be met by a multidisciplinary team approach exploiting better the skills of staff with varied professional backgrounds and harnessing technological advances that enable people even in the remotest areas to access care. The Brazilian experience argues strongly for multidisciplinary teams and decentralised planning at the state and municipal levels sup- 
ported by the national Ministry of Health. The evidence also suggests there will be efficiency gains from multiskilling and role enhancement of nursing and other staff.

In the medium term, continuing economic growth will be accompanied by a growing public demand for primary care to be delivered with high quality at affordable cost. Affordable health care in this situation requires three things: (i) effective prevention; (ii) most care being delivered effectively outside hospitals using generic drugs; (iii) access to hospital care to be prioritised according to need. This cannot be delivered through a hospital led service alone-it needs a cadre of primary care specialist staff trained in evidence based care and working to quality assured standards.

The lack of trained high quality staff in primary care to act as trainers and role models means that building a cadre of primary care specialists must be incremental and build on the few places where excellence already exists. Development will therefore have to be heavily supported by hospital staff. Establishment of a small number of centres of excellence may begin to meet the need for seeding high-quality trainers, teachers and researchers in primary care.

One advantage of the current lack of good primary care in India is the opportunity to innovate. There are good international examples of primary care improvement through innovations including outcome based funding and PPP commissioning-buying public services from private providers (for profit and not for profit). However, the key question is not whether the innovation can be effective but whether it will deliver in the local situation-what conditions have to be met for it to be implemented effectively. Answering this question usually requires incremental introduction of a new innovation and careful evaluation before scaling up. India is diverse and one size will never fit all. The UK too is now in an era of resource constraints, and can gain much from such shared learning opportunities.

The other main advantage of developing primary care at this moment in time is the rapid emergence of new technologies (information, electronic, and molecular). India has high level technological expertise and capacity in these areas which it will be able to exploit. It has the potential to leapfrog the UK in the employment of affordable diagnostics and mobile phone technology in primary care to reduce healthcare costs, to enable access to primary care in hard to reach areas, and to empower its population to self-manage their illnesses.

Finally, India has the major strategic advantage of a world leading generic pharmaceutical industry that is able to produce safe and effec- tive drugs and vaccines at low price. It therefore has the potential to provide preventive and chronic care to the highest international standard at a low cost. It needs to exploit this opportunity and developing a primary care formulary of simple effective drugs to be delivered by a strong primary care sector would do this.

\subsection{Summary of partnership opportunities} Education and training-This partnership opportunity exploits the fact that the UK has developed expertise in primary care that is not always readily available in India. Training in primary care needs to extend across all health professional disciplines including doctors, nurses, managers, and allied health professionals (fig 4). It needs to include continual professional development (CPD) to maintain and develop knowledge and skills. It could include IT facilitated distance learning. UK providers include the universities, professional organisations (such as the royal colleges), and medical publishers (who are increasingly interested in the opportunity provided by electronic media). Partnership arrangements are likely to provide two way benefit to the public and private institutions involved and to healthcare professionals in both countries.

Professional recognition and status-Fifty years ago general practice in the UK enjoyed very low status, and this situation was reversed through the leadership of the UK GMC and the Royal College of General Practitioners. Similarly, the development of enhanced nursing roles depended on the support of the UK Nursing Council and Royal College of Nursing. There is an opportunity for partnership between these UK institutions and their Indian counterparts to share experience and explore how to facilitate increased recognition and professional status for primary care in India.

Medical technology-This is another area where there is clear potential for two way benefit. India has great strength in both the IT and the diagnostics industries and has the potential to develop the affordable technologies cited by WHO as essential for care of non-communicable disease. A number of UK companies have strength in primary care specific information systems and UK universities have R\&D strength in the application of medical diagnostics and monitoring in primary care. The UK could be a test bed for innovative technological solutions to support patient self-care that might be rolled out later in an Indian setting. It would also be a potential European entry market for low cost, near patient devices, particularly for diagnosis and monitoring. NICE International can provide summarised evidence about the affordability of a number of medical technolo- gies, including the cost effectiveness of drugs, vaccines, and some diagnostic technologies.

Public-private partnership-State governments are aware that they are unlikely to be able to develop their public health systems without some significant input from the private sector. The NHS has always commissioned its primary care from independent contractors, recently not only from general practitioners but also commercial and social enterprise providers. India has introduced some very innovative PPP initiatives in the past five years. There is scope for mutual learning as well as partnership in the evaluation of existing programmes or roll-out of new programmes. It might even be worth exploring the potential to franchise NHS primary care in India.

Healthcare system design and governanceThe growing interest among many government and healthcare organisations in the work of the UK's National Institute for Clinical Excellence offers the potential for collaborations to enhance governance by supporting the development of clinical guidelines and quality standards appropriate for India. There is also scope for UK support in developing an Indian National Formulary for primary care. The DFID technical support teams are providing expertise to support reconfiguration of primary care systems with better governance in several states and the UK also has a number of commercial consulting firms with specific expertise in health system design. There is therefore scope for partnership with both public and private sectors in the design of new primary care initiatives and governance arrangements.

Research and development-Research and development in India is essential for evaluating health system innovations and in establishing a firm evidence-base for primary health care practice. There is potential for $R \& D$ partnerships in both the public and private sectors. A number of commercial agencies and universities in the UK have expertise in service evaluation and health services research on primary care issues, including evaluation of different health financing models and insurance schemes. Similarly, in developing and evaluating new affordable technologies for primary care, there is potential for partnership between a number of UK based diagnostic technology firms and experts in leading UK universities (for example, through the UK NIHR School for Primary Care Research) on aspects of innovative design, commercial partnership, product and market evaluation, and technological development, with their counterparts in India. And UK universities also have a track record in supporting the design and evaluation of affordable human resource solutions for primary care 


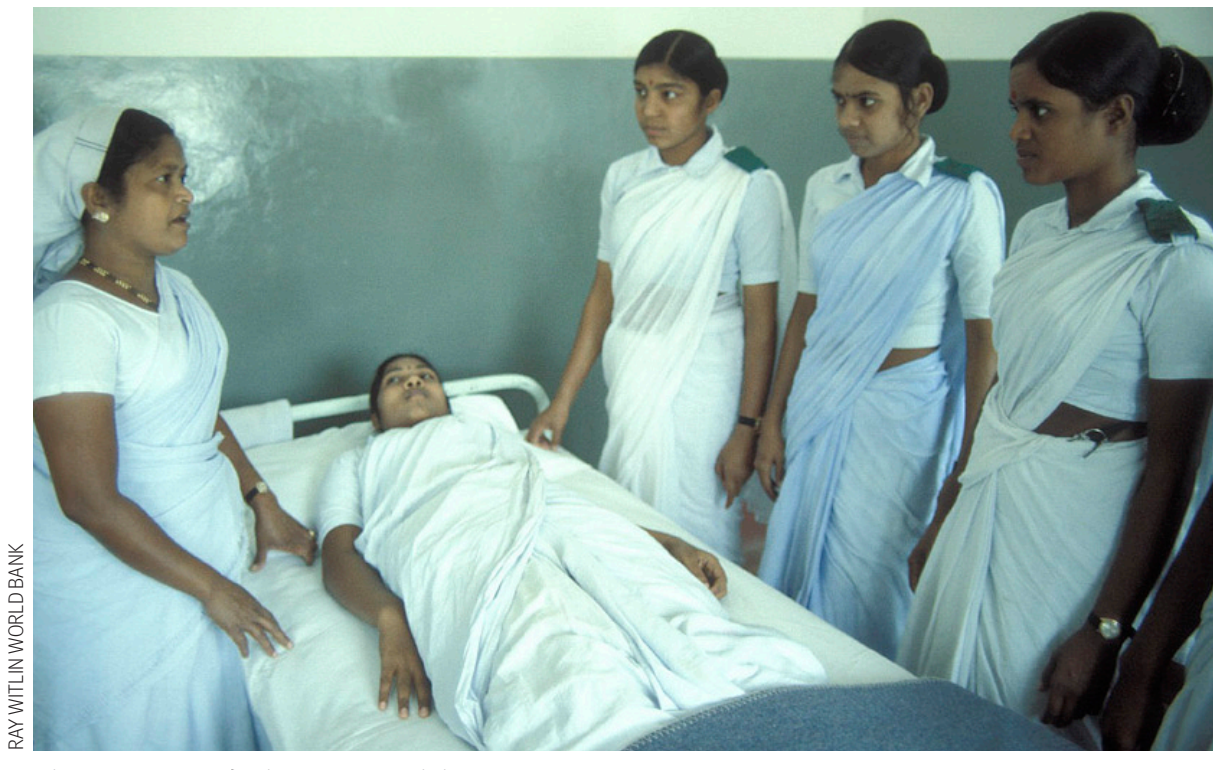

Fig 4 Nurses need primary care training too

which could be scaled-up in a resource-limited environment in both countries.

\subsection{Suggested way forward}

We suggest the CEO group considers facilitating the following activities:

- Development of a five year plan by the Government of India Ministry of Health and Family Welfare to ensure that all doctors working in primary care are trained and accredited in the specialty and have the necessary skills and competencies to deliver uniformly good quality care. We note that the Indian National Conference on Health Professions Education 2011 has made a similar recommendation, suggesting that the proposed new National Council on Human Resources for Health should have responsibility for setting standards and accrediting medical education. The UK GMC might be asked to provide support by sharing their experience with the Government of India and relevant bodies. The Indian Nursing Council may also wish to work with the UK Nursing and Midwifery Council in developing training and accreditation for enhanced nursing roles.

- Development of a series of evidence based clinical guidelines by the government, professional associations, and healthcare professionals working together for the delivery of primary care in India, perhaps by establishing an India NICE portal, which states could use to set quality standards and underpin clinical governance.

- Development of a primary care formulary of effective low cost generic drugs and vaccines to be made available through primary care; this would take advantage of ongoing efforts to improve the system for drug procurement and distribution.

- National support for a small number of states that are interested in developing primary care with UK support to act as national exemplars in:

- (i) Developing centres of excellence in primary care to increase leadership capacity and provide a new generation of primary care clinicians able to act as professional leaders, trainers, researchers, and university faculty members

- (ii) Implementing and evaluating innovative PPP initiatives focusing on providing care to meet both the MDG targets and the increasing challenge of chronic illness.

- It is further suggested that each participating state appoints a small functional India-UK team to oversee the development, with responsibility to set strategic and operational objectives, engage with all relevant stake holders, and exploit the opportunities for partnership outlined in this document.

- Support to incentivise institutional collaboration and develop training awards to take forward partnership opportunities identified in education, staff training, and primary care R\&D. Priorities for partnership might include the development and evaluation of: (i) affordable technologies to improve diagnosis and promote self-care; (ii) innovative training and governance solutions to improve the use of cheap effective medicines for chronic care; iii) innovative outcome based PPP commissioning to improve the care quality of existing primary care providers; (iv) application of new information technology to support provision of high quality care in remote areas without doctors; and (v) evaluation of different health financing models and insurance schemes.

- Initiation of a joint India-UK government collaboration to scope further the commercial opportunities and potential areas for collaboration in the primary healthcare sector outlined in this document, with a particular focus on e-health, primary care management systems, primary care pathways, diagnostics, and any other relevant areas in the primary care value chain (the chain of activities involved in delivering cost effective primary care).

Mala Rao professor, Institute for Health and Human Development, University of East London, London E15 4LZ,UK

David Mant professor, Oxford University Department of Primary Health Care, Oxford OX1 2ET, UK

Correspondence to:M Rao m.rao@uel.ac.uk

We thank DFID India, the Government of India's Ministry of Health and Family Welfare

and the Wellcome Trust for their support to the preparation of this document and the meeting held in Delhi (23-24

February 2012) to discuss its recommendations. We would like to specially thank David Lynn, Phil Green and Susannah Cleary at the Wellcome Trust and Billy Stewart at DFID India for their detailed inputs and individual contributions to the development of this white paper.

Contributors and sources: The following people contributed to this document: Kalipso Chalkidou, NICE International; Chayan Datta, Royal College of General Practitioners; Shah Ebrahim, London School of Hygiene and Tropical Medicine; David Griffith, Options Consultancy Services; Andy Haines, London School of Hygiene and Tropical Medicine; Dee Kyne, Pathfinder Health India Pvt Ltd; Garth Manning, Royal College of General Practitioners; David Mant, University of Oxford; Irwin Nazareth, University College London; Niti Pall, Pathfinder Health India Pvt Ltd; Richard Porter, UKTrade and Investment; Jo Pritchard, Central Surrey Health; Mala Rao, University of East London; Liam Smeeth, London School of Hygiene and Tropical Medicine; Billy Stewart, DFID India; Andrew Wardle, Royal College of Nursing; and Richard Yarwood, Haymarket Media Group

Competing interests: All authors have completed the ICMJE uniform disclosure form at www.icmje.org/coi_disclosure. pdf (available on request from the corresponding author) and declare: no support from any organisation for the submitted work; no financial relationships with any organisations that might have an interest in the submitted work in the previous three years; no other relationships or activities that could appear to have influenced the submitted work.

Provenance and peer review: Invited; not externally peer reviewed.

1 Government of India. 11th five year plan. http:// planningcommission.gov.in/plans/planrel/ fiveyr/11th/11 v2/11v2_ch3.pdf.

2 Government of India. Faster, sustainable and more inclusive growth: an approach to the 12 th five year plan. http://planningcommission.nic.in/plans/ planrel/12appdrft/appraoch_12plan.pdf.

3 Roland M. The Quality and Outcomes Framework: too early for a final verdict. BrJ Gen Practice 2007;57:525-7.

4 Starfield B. Is primary care essential?Lancet 1994:344:1129-33

5 Starfield B. The Importance of Primary Health Care in Health Systems, QATAR-EMRO, Primary Healthcare 
Conference. DOHA, QATAR. http://gis.emro.who.int/ HealthSystemObservatory/Workshops/QatarConference/ PPt\%20converted\%20to\%20PDF/Day\%202/P\%20 Reg\%20xperiences\%20and\%20Innovative\%20 Solution/Dr\%20B.\%20Starfield\%20-\%20 Importance\%20of\%20PC.pdf.

6 RawafS, De Maeseneer J, Starfield B. From Alma Ata to Almaty: a new start for primary health care. Lance 2008;372:1375-67.

7 Macinko I, Guanais FC, de Fátima M, de Souza M. Evaluation of the impact of the Family Health Program on infant mortality in Brazil, 1990-2002. J Epidemiol Community Health 2006:60:13-9.

8 Department of Health. GP patient survey 2007. www. dh.gov.uk/en/Publicationsandstatistics/PublishedSurvey/ GPpatientsurvey2007/index.htm.

9 Central Surrey Health. Treating health care differently www. centralsurreyhealth.nhs.uk/page/index.

10 Laurant M, Reeves D, Hermens R, Braspenning J, Grol R, Sibbald B. Substitution of doctors by nurses in primary care. Cochrane Database Syst Rev 2005;2:CD001271.

11 Victora CG. The Millennium Development Goals and the inverse care law: no progress where it is most needed? । Epidemiol Community Health 2008;62:938-9.

12 Lagarde M, Palmer N. The impact of user fees on access to health services in low- and middle-income countries. Cochrane Database SystRev 2011:4:CD009094.

13 Kamat VR. Reconsidering the popularity of primary health centers in India: a case study from rural Maharashtra. Soc SciMed 1995;41:87-98.

14 Kumar AK, Chen LC, Choudhury M, Ganju S, Mahajan V, Sinha A, et al. Financing healthcare for all: challenges and opportunities. Lancet 2011;377:668-79.

15 Gill K. Primary evaluation of service delivery under the NRHM.; findings from a study in Andhra Pradesh, Uttar Pradesh, Bihar and Rajasthan. Working Paper 1/2009. PEO Planning Commission for India, 2009.

16 National Rural Health Mission. Annual review 2010. http:// mohfw.nic.in/NRHM.htm

17 More NS, Bapat U, Das S, Patil S, Porel M, Vaidya L, et al. Cluster-randomised controlled trial of community mobilisation in Mumbai slums to improve care during pregnancy, delivery, postpartum and for the newborn. Trials 2008;9:7

18 Kounteya Sinha. NRHM paints a poor picture of health facilities. The Hindu 2010 Jan 27. http:// articles.timesofindia.indiatimes.com/2010-01-27/ india/28141070 1 essential-medicines-prescriptioncostlier-drugs.

19 WHO Country Office for India. Not enough here, too many there. Health Workforce in India. WHO, 2007:42.

20 Rao M, Rao KD, Kumar AK, Sundararaman T. Human resources for health in India. Lancet 2011;377:587-98.

21 Rao M, Clarke A, Sanderson C, Hammersley R. Patients own assessments of quality of primary care compared with objective records based measures of technical quality of care: cross sectional study. BM/ 2006;333:19-22.
22 Reddy KS, Patel V, Jha P, Paul VK, Kumar AKS, Dandoni L, et al. Towards achievement of universal health care in India by 2020:a call to action. Lancet 2011;377:760-8.

23 National Conference on Health Professions Education 2011. Concluding statement. The Hindu 2011 Oct 19. www.thehindu.com/news/resources/article2551581. ece\#.Tqi8zkY8N5w.mailto.

24 Das J, Hammer J. Money for nothing: the dire straits of medical practice in Delhi, India. J DevEcon 2007;83:1-36.

25 Kouteya Sinha. Planning commission backs shortened medical degree for rural areas. Times of India $2011 \mathrm{Sep}$ 26. http://articles.timesofindia.indiatimes.com/2011-0926/india/30203913_1_rural-areas-rural-medicine-ruralhealth-practitioners.

26 Mickan S, Hoffman SJ, Nasmith L, World Health Organizations Study Group on Interprofessional Education and Collaborative Practice. Collaborative practice in a global health context: Common themes from developed and developing countries. J Interprof Care 2010;24:492502 .

27 Hurst K. Multiskilled health carers: nature, purpose and implications. Health Manpow Manage 1997;23:197-211.

28 Sundararaman T, Gupta G. Indian approaches to retaining skilled health workers in rural areas. Bull World Health Organ 2011;89:73-7.

29 Paul VK, Sachdev HS, Mavalankar D, Ramachandran P, Sankar MJ, Bhandari N, et al. Reproductive health, and child health and nutrition in India: meeting the challenge. Lancet 2011;377:332-49.

30 International Institute for Population Sciences. District level household survey (DHLS-3), India 2007-8. IIPS, 2008.

31 Bhutta ZA, Chopra M, Axelson H, Berman P, Boerma T, Bryce J, et al. Countdown to 2015 decade report (200010): taking stock of maternal, newborn, and child survival. Lancet 2010;375:2032-44.

32 Bajpai N, Sachs J, Dholakia RH. Improving access, service delivery and efficiency of the public health system in rural India: mid-term evaluation of the NRHM. Columbia University 2009.

33 Paul VK. India: conditional cash transfers for in-facility deliveries. Lancet 2010;375:1943-4.

34 Padmanaban P, Raman PS, Mavalankar DV. Innovations and challenges in reducing maternal mortality in Tamil Nadu, India. J Health Popul Nutr 2009;27:202-19.

35 Harris M, Haines A. Brazil's family health programme. BMJ 2010;341:C4945.

36 Tripathy P, Nair N, Barnett S, Mahapatra R, Borghi J, Rath S, et al. Effect of a participatory intervention with women's groups on birth outcomes and maternal depression in Jharkhand and Orissa, India: a cluster-randomised controlled trial. Lancet 2010;375:1182-92.

37 USAID. Key indicators for urban poor in India. http://uhrc in/downloads/Factsheet-India.pdf.

38 Haines A, Sanders D, Lehmann U, Rowe AK, Lawn JE, Jan S, et al. Achieving child survival goals: potential contribution of community health workers. Lancet 2007;369:2121-31.

39 Lewin S, Munabi-Babigumira S, Glenton C, Daniels K,
Bosch-Capblanch X, van Wyk BE, et al. Lay healthworkers in primary and community health care for maternal and child health and the management of infectious diseases. Cochrane Database Syst Rev 2010;3:CD004015.

40 Patel V, Kumar AK, Paul VK, Rao KD, Reddy KS. Universal health care in India: the time is right. Lancet 2011;377:448-9

41 Gupta SK, Singh Z, Purty AJ, Kar M, Vedapriya DR, Mahajan $P$, et al. Diabetes prevalence and its risk factors in rural are of Tamil Nadu. Indian J Community Med 2010;35:396-9.

42 Mant D. Prevention. Lancet 1994;344:1343-6.

43 Griffin S. Diabetes care in general practice: meta-analysis of randomised control trials. BMJ 1998:317:390-6.

44 Doran T, Kontopantelis E, Valderas JM, Campbell S, Roland M, Salisbury C, et al. Effect of financial incentives on incentivised and non-incentivised clinical activities: longitudinal analysis of data from the UK Quality and Outcomes Framework. BMJ 2011;342:d3590.

45 Patel V, Weiss HA, Chowdhary N, NaikS, PednekarS, Chatterjee S, et al. Effectiveness of an intervention led by lay health counsellors for depressive and anxiety disorders in primary care in Goa, India (MANAS): a cluster randomised controlled trial. Lancet 2010:376:2086-95.

46 Dias A, Dewey ME, D’Souza J, Dhume R, Motghare DD, Shaji KS, et al. The effectiveness of a home care program for supporting caregivers of persons with dementia in developing countries: a randomised controlled trial from Goa, India. PLoS One 2008;3:e2333.

47 Starfield B. The future of primary care: refocusing the system. NEnglJ Med 2008;359:2087-91.

48 Heneghan C, Alonso-Coello P, Garcia-Alamino JM, Perera R, Meats E, Glasziou P et al. Self-monitoring of oral anticoagulation: a systematic review and meta-analysis. Lancet 2006;367:404-11

49 Thoolen B, De Ridder D, Bensing J, Maas C, Griffin S, Gorte $\mathrm{K}$, et al. Effectiveness of a self-management intervention in patients with screen-detected type 2 diabetes. Diabetes Care 2007;30:2832-7.

50 Bray EP, Holder R, Mant J, McManus RJ. Does selfmonitoring reduce blood pressure? Meta-analysis with meta-regression of randomized controlled trials. Ann Med 2010;42:371-86

51 WHO. Package of essential noncommunicable disease interventions. 2011. http://whqlibdoc.who.int/ publications/2010/9789241598996_eng.pdf

52 Patel V, Vaidya R, Naik D, Borker P. Irrational drug use in India: a prescription survey from Goa. J Postgrad Med 2005;51:9-12.

53 Sudarshan H, Prashanth NS. Good governance in health care: the Karnataka experience. Lancet 2011;377:790-2.

54 Vision 2015. Medical Council of India March 2011. www. mciindia.org/tools/announcement/MCl_booklet.pdf.

55 Rao K, Bhatnagar A, Berman P. India's health workforce: size, composition and distribution. India's Health Beat 2009;1(3). www.hrhindia.org/assets/images/HRH\%20 Policy\%20Note3.pdf.

Cite this as: $B M / 2012 ; 344: \mathrm{e} 3151$ 